\title{
МАГНИТНЫЕ СОРБЕНТЫ НА ОСНОВЕ КОРЫ СОСНЫ ДЛЯ СБОРА НЕФТИ И НЕФТЕПРОДУКТОВ
}

\author{
() Е.В. Веприкова, С.И. Цыганова", Е.А. Терещенко
}

\author{
Институт химии и химической технологии СО РАН, Академгородок, 50/24, \\ Красноярск, 660036 (Россия), e-mail: light@icct.ru
}

\begin{abstract}
Показана возможность получения магнитных сорбентов из коры сосны, модифицированной различным количеством хлорида железа. Установлено влияние содержания модификатора в коре на характеристики пористой структуры получаемых сорбентов и на их поглотительную способность в отношении нефти и моторного масла. Определено количество хлорида железа (15 мас.\%), обеспечивающего синтез магнитного сорбента с оптимальным сочетанием магнитных свойств и емкости в отношении нефтепродуктов для полного удаления их с поверхности воды. Показано, что эти сорбенты по нефте-, маслоемкости и плавучести не уступают промышленным нефтесобирателям и обладают низким водопоглощением.

Ключевые слова: магнитные сорбенты, кора сосны, нефтеемкость, водопоглощение.
\end{abstract}

\section{Введение}

Создание сорбентов из отходов древесины, в частности коры сосны, представляется актуальным направлением ввиду скопления огромного количества коры при промышленной переработке сосны. Основная часть подобных отходов утилизируется сжиганием или вывозится в отвалы, хотя кора сосны является ценным потенциальным сырьем для производства материалов с практически важными свойствами. Так, сосновая кора является незаменимым источником получения разнообразных экстрактивных веществ - дубильных веществ, проантоцианидинов, пектина и др. $[1,2]$. Перспективным направлением утилизации отходов коры сосны является компостирование с целью получения удобрений, которые улучшают структуру и гумусовое состояние почвы [3, 4]. Из коры сосны можно получать сорбционные материалы различного назначения. Например, в литературе описаны свойства сорбентов, позволяющие очищать воду от примеси красителей и тяжелых металлов [5-7]. Также сорбенты из коры сосны можно использовать для удаления нефти и нефтепродуктов [8].

Для удаления нефтяных загрязнений весьма эффективны сорбенты с магнитными свойствами. Применение таких материалов дает возможность удалять нефтяные загрязнения с поверхностей различной природы методами магнитной сепарации. Вовлечение различных древесных отходов в производство магнитных нефтесобирателей позволяет минимизировать количество таких отходов и снизить себестоимость получаемых сорбентов.

Цыганова Светлана Ивановна - старший научный сотрудник лаборатории процессов синтеза и превращения углеводородов, e-mail: light@icct.ru

Веприкова Евгения Владимировна - старший научный сотрудник лаборатории процессов синтеза и превращения углеводородов, e-mail: veprikova2@mail.ru

Терещенко Елена Анатольевна - ведущий инженер, лаборатория процессов синтеза и превращения углеводородов, e-mail: tereshea@yandex.ru
В литературе описан процесс получения магнитных композитных сорбентов из древесины березы и показана возможность их использования для сбора нефти и нефтепродуктов $[9,10]$.

Цель данной работы - изучение возможности применения магнитных сорбентов из модифицированной хлоридом железа коры сосны для сбора нефти и нефтепродуктов.

\footnotetext{
* Автор, с которым следует вести переписку.
} 


\section{Экспериментальная часть}

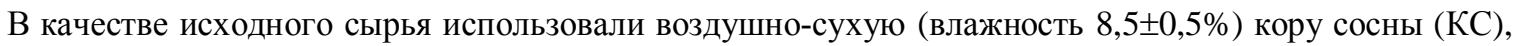
отобранную из отходов Красноярского ЛДК. Кора содержала (\% от массы абсолютно сухого вещества): экстрактивных веществ - 12,4; водорастворимых веществ - 11,4; легкогидролизуемых полисахаридов 13,6; трудногидролизуемых полисахаридов - 25,4; негидролизуемого остатка - 37,2. Экстрактивные вещества выделяли экстрагированием коры сосны спирто-толуольной смесью при соотношении растворителей $1: 2$ соответственно. Количество негидролизуемого остатка (смесь лигнина и таннинов) определяли по методу Комарова. Содержание минеральных примесей в коре составляло 2,6\%. Кору измельчали на дезинтеграторе марки «8255 Nossen» (Германия) и отбирали фракцию с размером частиц менее 0,5 мм.

Для получения магнитных сорбентов исходную кору сосны модифицировали пропиткой водным раствором $\mathrm{FeCl}_{3}$ различной концентрации. Количество $\mathrm{FeCl}_{3}$, вводимого в сырье, варьировали от 5 до 25 мас.\%. Влажные образцы модифицированной коры сосны (МКС) выдерживали в герметично закрытой посуде при комнатных условиях в течение 24 ч при периодическом перемешивании. Затем сушили до постоянного веса при температуре $(90 \pm 5){ }^{\circ} \mathrm{C}$. Модифицированную кору сосны карбонизировали в реакторе проточного типа до температуры $800{ }^{\circ} \mathrm{C}$ (скорость нагрева $10{ }^{\circ} \mathrm{C} /$ мин) в токе аргона. Продолжительность изотермической выдержки при конечной температуре составляла 30 мин.

Определение суммарного объема пор по влагоемкости $\left(\mathrm{V}_{\Sigma}\right)$ проводили согласно ГОСТ 8858-93 (ИСО 1018-75). Удельную поверхность $\left(\mathrm{S}_{\mathrm{yд}}\right)$ определяли методом тепловой десорбции азота на приборе Сорбтометр-М.

Определение водорастворимого железа в сорбентах проводили по методике ГОСТ 4453-74. Концентрацию железа в воде определяли атомно-абсорбционным методом на приборе Analyst-400.

Показатели нефтеемкости (HE, г/г), маслоемкости (ME, г/г) и водопоглощения (ВП, г/г) сорбентов,

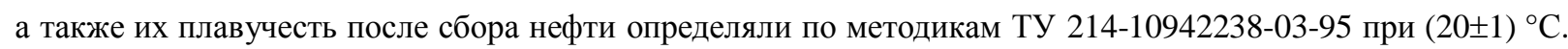
Нефте- и маслоемкость устанавливали по сырой нефти Тюменского месторождения $\left(\rho=0,85\right.$ г/см $\left.{ }^{3}\right)$ и моторному маслу $\left(\rho=0,89\right.$ г/ $\left.\mathrm{cm}^{3}\right)$. Все представленные в работе результаты являются усредненным значением трех измерений. Ошибка определения НЕ, МЕ и ВП не превышала 7,5\%.

Регистрацию ИК-спектров образцов осуществляли на ИК-Фурье спектрометре Tensor 27 (Bruker, Германия) в области 4000-400 см . $^{-1}$ Обработка спектральной информации проведена с использованием пакета программ OPUS, версия 5.5. Образцы для получения ИК-спектров готовили в виде таблеток в матрице бромистого калия. Условия приготовления образцов (концентрация вещества в матрице, время перемешивания с бромистым калием, давление прессования, время вакуумирования) были одинаковы.

\section{Обсуждение результатов}

Данные таблицы 1 показывают, что на основе коры сосны можно получать сорбенты с выходом 35 мас.\%. Причем модификация коры сосны хлоридом железа приводит к увеличению выхода сорбентов. Использование $\mathrm{FeCl}_{3}$ в качестве модификатора приводит к существенному увеличению значений удельной поверхности и уменьшению суммарного объема пор по сравнению с сорбентами, полученными из немодифицированной коры. Очевидно, к этому приводит развитие микро- и мезопор в структуре сорбента на фоне уменьшения макропор [11].

Было установлено, что получаемые сорбенты независимо от количества модификатора не содержат водорастворимых веществ, включая примеси железа. В результате сопоставления ИК-спектров были выявлены различия для сорбентов, полученных из исходной и модифицированной $\mathrm{FeCl}_{3}$ коры сосны (рис. 1).

Таблица 1. Характеристики сорбентов, полученных из исходной (КС) и модифицированной (МКС) коры сосны при температуре $800{ }^{\circ} \mathrm{C}$

\begin{tabular}{c|c|c|c|c}
\hline Исходный образец & Содержание $\mathrm{FeCl}_{3}$ в КС, мас. $\%$ & $* \mathrm{P}$, мас. $\%$ & $* \mathrm{~V}_{\Sigma}, \mathrm{cm}^{3} / \Gamma$ & $* \mathrm{~S}_{\mathrm{yд}}, \mathrm{M}^{2} / \Gamma$ \\
\hline КС & 0 & 35,5 & 0,95 & 62,5 \\
МКС-1 & 5 & 38,8 & 0,58 & 237,5 \\
МКС-2 & 15 & 41,5 & 0,52 & 350,1 \\
МКС-3 & 25 & 38,9 & 0,47 & 524,6 \\
\hline
\end{tabular}

* P - выход, $\mathrm{V}_{\Sigma}-$ суммарный объем пор по влагоемкости (ГОСТ 8858-93), $\mathrm{S}_{\text {уд }}$ - удельная поверхность по БЭТ. 
Рис. 1. ИК-спектры сорбентов из исходной и модифицированной коры сосны: 1 - КС; 2 - МКС-1; 3 - МКС-2; 4 - МКС-3

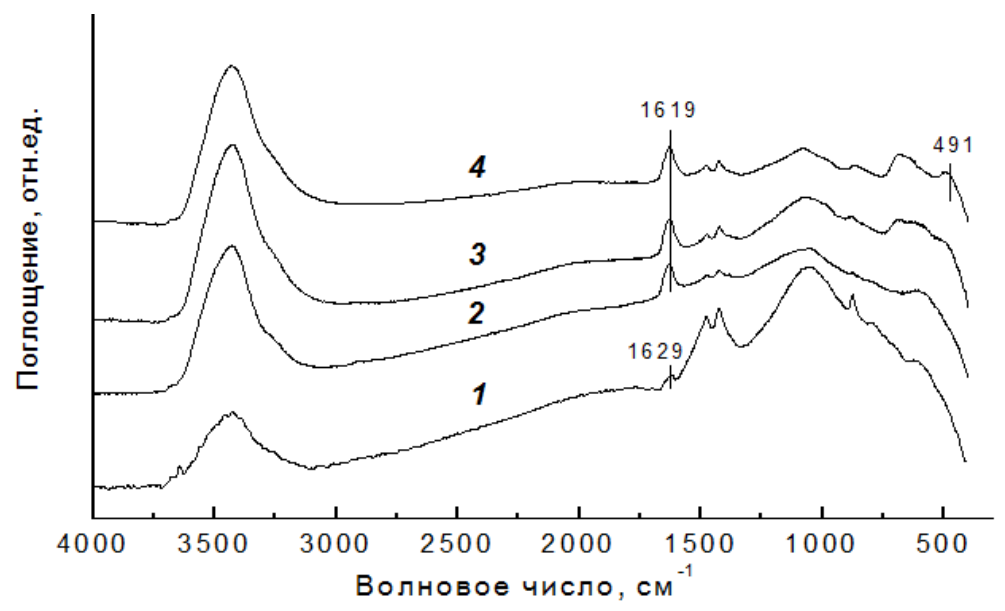

Так, в ИК-спектрах сорбентов из модифицированной коры сосны присутствуют интенсивные полосы поглощения с максимумом 3429-3432 cм ${ }^{-1}$, обусловленные валентными колебаниями ОН-групп различной природы, связанных водородными связями. Использование $\mathrm{FeCl}_{3}$ в качестве модификатора приводит к сдвигу максимума полосы поглощения $1629 \mathrm{~cm}^{-1}$, наблюдаемой в спектре немодифицированного сорбента КС, в область высокочастотных колебаний. Поглощение в этой области обусловлено валентными колебаниями $\mathrm{C}=\mathrm{O}$ связей в различных соединениях и плоскостными колебаниями сопряженных $\mathrm{C}=\mathrm{C}$ связей в ароматических структурах [12].

Следует отметить, что интенсивность полос в области $1480-850 \mathrm{~cm}^{-1}$ в спектрах сорбентов из модифицированной коры ниже по сравнению с интенсивностью полос в спектре сорбента из исходной коры.

Наблюдаемые высокочастотные максимумы в области 750-400 см-1 в спектре сорбента из $\mathrm{FeCl}_{3}$ содержащей коры можно отнести к колебанию связи металл-углерод, металл-кислород, которые заметно выше в спектре сорбента с 25 мас.\% $\mathrm{FeCl}_{3}$. Эта область поглощения также является характеристической полосой в спектре магнетита $[9,12]$ и, по-видимому, свидетельствует о присутствии его в сорбентах. Более того, представленные в ранней работе [9] результаты РФА сорбентов, полученных из опилок березы с добавкой $\mathrm{FeCl}_{3}$ в тех же условиях, подтверждают присутствие в них фазы магнетита.

Исследования поведения сорбентов из $\mathrm{FeCl}_{3}$-содержащей коры в поле постоянного магнита показали, что сорбенты из коры, модифицированной 15 и 25 мас.\% хлорида железа, обладают лучшей способностью притягиваться к магниту, чем сорбент из КС с 5 мас.\% $\mathrm{FeCl}_{3}$.

Наличие развитой пористой структуры и магнитных свойств, полученных из коры сосны сорбентов, стали основанием для изучения возможности их применения в качестве нефтесобирателей.

Свойства сорбентов из коры сосны, позволяющие оценить их эффективность для сбора нефти и нефтепродуктов, приведены в таблице 2. Видно, что сорбенты из коры сосны по своей нефтеемкости не уступают промышленным нефтесобирателям различной природы, а по емкости в отношении моторного масла превосходят их. Важным преимуществом сорбентов из коры (КС и МКС) является низкое водопоглощение, которое позволяет применять их для сбора тонких пленок нефти и нефтепродуктов с поверхности воды $[13,14]$.

Сорбенты из коры сосны демонстрируют высокую плавучесть после сбора нефти и нефтепродуктов, что создает резерв времени для проведения мероприятий по сбору отработанных сорбентов с поверхности воды.

Испытания по пребыванию нефтенасыщенных сорбентов на поверхности воды в течение 240 ч показали, что только сорбенты из коры сосны и сорбент МТУ (макропористый технический углерод, полученный карбонизацией древесных опилок [13]) сохраняют свою 100\% плавучесть в отличие от промышленных нефтесобирателей на основе природного сырья Turbo-Jet и Сибсорбент.

Важно отметить, что эффективность применения магнитных сорбентов определяется не только их нефтеемкостью, но и несложного способа сбора нефтяной пленки с поверхности воды с помощью магнита.

Процесс сбора нефтяной пленки после нанесения сорбента представлен на рисунке 2.

Установлено, что нанесение сорбентов из модифицированной хлоридом железа коры сосны приводит к стягиванию нефтяного пятна в среднем на $15 \%$. 
Таблица 2. Свойства сорбентов из коры сосны и промышленных нефтесобирателей

\begin{tabular}{|c|c|c|c|c|c|c|}
\hline \multirow{2}{*}{ Сорбент } & \multirow{2}{*}{ Сырье для получения } & \multirow{2}{*}{$\mathrm{HE}, \Gamma / \Gamma$} & \multirow{2}{*}{$\mathrm{ME}, \Gamma / \Gamma$} & \multirow{2}{*}{ ВП, г/г } & \multicolumn{2}{|c|}{ Плавучесть **, \% } \\
\hline & & & & & 72 ч & 240 ч \\
\hline KC & Кора сосны & 3,4 & 4,2 & 0,5 & 100 & 100 \\
\hline МКС-1 & $\mathrm{KC}+5$ мас. $\% \mathrm{FeCl}_{3}$ & 4,3 & 4,5 & 0,4 & 100 & 100 \\
\hline МКС-2 & $\mathrm{KC}+15$ мас. $\% \mathrm{FeCl}_{3}$ & 3,5 & 4,5 & 0,3 & 100 & 100 \\
\hline МКC-3 & $\mathrm{KC}+25$ мас. $\% \mathrm{FeCl}_{3}$ & 3,2 & 4,4 & 0,3 & 100 & 100 \\
\hline Сибсорбент (Россия) & Сапропель, торф, мох & 2,6 & 4,0 & 2,0 & 100 & 46,8 \\
\hline Turbo - Jet (Франция) & Торф & 3,6 & 3,9 & 2,0 & 98 & 72,3 \\
\hline MTУ & Древесные опилки & $2,5-4,1 *$ & 4,0 & $1,0^{*}$ & 100 & 100 \\
\hline
\end{tabular}

Примечание. НЕ, МЕ, ВП - нефтеемкость, маслоемкость и водопоглощение; * - данные работы [13];** - плавучесть сорбента после сбора нефти.
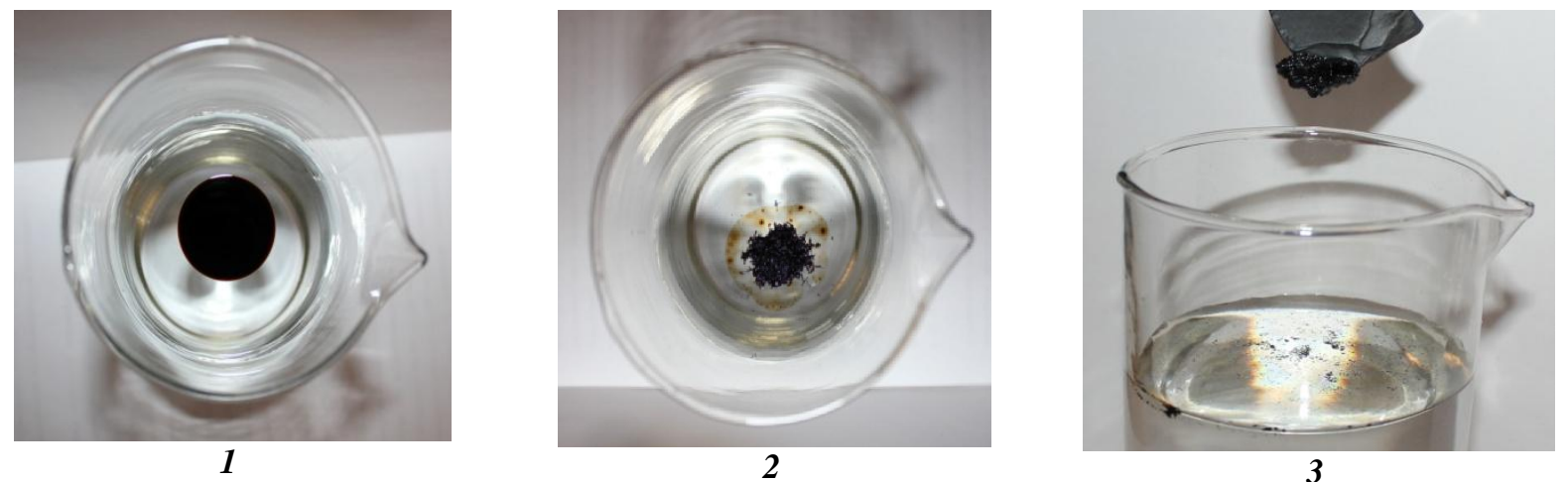

Рис. 2. Процесс сбора нефти с помощью магнитного сорбента (МКС-2) и магнита (1 - исходное нефтяное пятно; 2 - нефтяное пятно после добавки сорбента; 3 - удаление нефтяного пятна магнитом)

Хотя сорбент МКС-1 имеет лучшую нефтеемкость, по своим магнитным свойствам он существенно уступает другим Fе-содержащим сорбентам. В результате пленку нефти после нанесения этого сорбента не удается удалить магнитом. Только сорбенты МКС-2 и МКС-3 обеспечивают магнитную восприимчивость пленки нефти, достаточную для полного удаления ее постоянным магнитом.

Отметим, что для получения сорбента с оптимальным сочетанием магнитных свойств и емкости в отношении нефти и моторного масла достаточно вводить в кору 15 мас.\% хлорида железа (табл. 2). По своей нефтеемкости такой сорбент превосходит магнитные сорбенты из древесных опилок, полученные в аналогичных условиях [10].

\section{Выводы}

Получены магнитные сорбенты из коры сосны, модифицированной различным содержанием хлорида железа. Показано, что с ростом содержания хлорида железа в исходном образце повышается выход и удельная поверхность углеродного продукта.

Установлено, что Fe-содержащие сорбенты из коры сосны по нефте-, маслоемкости и плавучести не уступают промышленным нефтесобирателям, а низкое водопоглощение полученных сорбентов позволяет создать существенное временное преимущество для сбора нефтеразлива с поверхности воды.

Показано, что сорбент из коры, модифицированный 15 мас.\% хлорида железа, обладает оптимальным сочетанием магнитных свойств и емкости в отношении нефтепродуктов для полного удаления их с поверхности воды.

Авторы выражают благодарность за помощь в работе Красноярскому региональному центру коллективного пользования СО РАН.

\section{Список литературь}

1. Дейнеко И.П., Дайнеко И.В., Белов Л.П. Исследование химического состава коры сосны // Химия растительного сырья. 2007. №1. С. 19-24.

2. Бутылкина А.И., Левданский В.А., Кузнецов Б.Н. Изучение состава экстрактивных веществ, выделенных из коры сосны различными методами // Химия растительного сырья. 2011. № 2. С. 77-82. 
3. Ушанова В.М., Заика Н.А., Громовых Т.И. Альтернативные пути использования коры хвойных в различных технологиях // Химия и химическая технология. 2006. Т. 49. Вып. 5. С. 72-77.

4. Дейнеко И.П., Дайнеко И.В., Корнилова Л.И. Окислительный аммонолиз древесной коры // Журнал прикладной химии. 2002. Т. 75, вып. 3. С. 502-505.

5. Семенович А.В., Лоскутов С.Р. Адсорбция катионных красителей модифицированной корой хвойных древесных пород // Химия растительного сырья. 2004. №3. С. 121-125.

6. Патент 2176617 (РФ). Способ очистки сточных вод от тяжелых металлов / И.С. Гелис. 10.12.2001.

7. Хохотва А.П. Адсорбция тяжелых металлов сорбентом на основе сосновой коры // Химия и технология воды. 2010. T. 32, №6. С. 604-612.

8. Семенович А.В., Лоскутов С.Р., Пермякова Г.В. Сбор проливов нефтепродуктов модифицированной корой хвойных пород // Химия растительного сырья. 2008. №6. С. 113-117.

9. Ц Цыганова С.И., Бондаренко Г.П., Королькова И.В., Фетисова О.Ю., Каргин В.Ф., Великанов Д.А. Синтез высокопористого углеродистого материала с магнитными свойствами // Журнал прикладной химии. 2011. Т. 84, вып. 12. С. 2047-2052.

10. Цыганова С.И., Веприкова Е.В., Терещенко Е.А., Фетисова О.Ю. Синтез магнитных нефтесобирателей на основе модифицированных опилок древесины // Экология и промышленность России. 2014. Июнь. С. 18-21.

11. Кельцев Н.В. Основы адсорбционной техники. М., 1976. 512 с.

12. Infrared and Raman characteristic group frequencies: Tables and charts / G. Socrates. John Wiley-Sons, 2004. 347 p.

13. Хлесткин Р.Н., Самойлов Н.А., Осипов М.И., Чичирко О.П. Технологии сбора нефти с места аварийного разлива при помощи макропористого технического углерода // Нефтяное хозяйство. 2005. №11. С. 111-113.

14. Самойлов Н.А., Хлесткин Р.Н., Шеметов А.В., Шаммазов А.А. Сорбционный метод ликвидации аварийных разливов нефти и нефтепродуктов. М., 2001. 189 с.

Поступило в редакиию 11 февраля 2015 г.

После переработки 20 марта 2015 г. 
Veprikova E.V., Tsyganova S.I. ${ }^{*}$ Tereshchenko E.A. MAGNETIC SORBENTS BASED ON THE PINE BARK FOR OIL-SPILL AND OIL PRODUCTS RECOVERY

Institute of Chemistry and Chemical Technology, Siberian Branch of the Russian Academy of Sciences,

Akademgorodok, 50/24, Krasnoyarsk, 660036 (Russia), e-mail: light@icct.ru

Magnetic sorbents from bark pine sawdust, modified different content of iron chloride were synthesized. The optimum content of the modifier in the bark pine was determined for synthesis of magnetic sorbent and for complete removal of the oil film from the water surface. It has been shown that these sorbents for oil absorption, water absorption and buoyancy are not inferior to the nonmagnetic industrial sorbents and have low water absorption.

Keywords: magnetic sorbents, pine bark, oil capacity, water absorption.

\section{References}

1. Deineko I.P., Daineko I.V., Belov L.P. Khimiia rastitel'nogo syr'ia, 2007, no. 1, pp. 19-24. (in Russ.).

2. Butylkina A.I., Levdanskii V.A., Kuznetsov B.N. Khimiia rastitel'nogo syr'ia, 2011, no. 2, pp. 77-82. (in Russ.).

3. Ushanova V.M., Zaika N.A., Gromovykh T.I. Khimiia i khimicheskaia tekhnologiia, 2006, vol. 49, issue 5, pp. 72-77. (in Russ.).

4. Deineko I.P., Daineko I.V., Kornilova L.I. Zhurnal prikladnoi khimii, 2002, vol. 75, issue 3, pp. 502-505. (in Russ.).

5. Semenovich A.V., Loskutov S.R. Khimiia rastitel'nogo syr'ia, 2004, no. 3, pp. 121-125. (in Russ.).

6. $\quad$ Patent 2176617 (RU). 2001. (in Russ.).

7. Khokhotva A.P. Khimiia i tekhnologiia vody, 2010, vol. 32, no. 6, pp. 604-612. (in Russ.).

8. Semenovich A.V., Loskutov S.R., Permiakova G.V. Khimiia rastitel'nogo syría, 2008, no. 6, pp. 113-117. (in Russ.).

9. Tsyganova S.I, Bondarenko G.P., Korol'kova I.V., Fetisova O.Iu., Kargin V.F., Velikanov D.A. Zhurnal prikladnoi khimii, 2011, vol. 84, issue 12, pp. 2047-2052. (in Russ.).

10. Tsyganova S.I., Veprikova E.V., Tereshchenko E.A., Fetisova O.Iu. Ekologiia i promyshlennost' Rossii, 2014, June, pp. 18-21. (in Russ.).

11. Kel'tsev N.V. Osnovy adsorbtsionnoi tekhniki. [Fundamentals of adsorption technology]. Moscow, 1976, 512 p. (in Russ.).

12. Infrared and Raman characteristic group frequencies: Tables and charts / G. Socrates. John Wiley-Sons, 2004. 347 p.

13. Khlestkin R.N., Samoilov N.A., Osipov M.I., Chichirko O.P. Neftianoe khoziaistvo, 2005, no. 11, pp. 111-113. (in Russ.).

14. Samoilov N.A., Khlestkin R.N., Shemetov A.V., Shammazov A.A. Sorbtsionnyi metod likvidatsii avariinykh razlivov nefti i nefteproduktov. [Sorption methods of oil spill response and oil]. Moscow, 2001, 189 p. (in Russ.).

Received February 2, 2014

Revised March 20, 2015

\footnotetext{
* Corresponding author.
} 